The challenge of achieving transparency in undergraduate honours-level dissertation supervision

\author{
Mary Malcolm \\ University of Bedfordshire \\ https://orcid.org/0000-0003-3907-6718
}

\begin{abstract}
The undergraduate honours-level dissertation is a significant component of many UK undergraduate programmes, as a key stage in the longer-term intellectual and career development of potential researchers and knowledge-workers, and also a critical contributor to immediate award outcome. This study aims to identify how dissertation supervisors balance and deliver on these expectations. Qualitative analysis of twenty interviews conducted with supervisors at two post-1992 UK universities identifies how supervisors construct supervision as a multi-stage process. Supervisors describe how their individual supervisory practices enable them to maintain initial control of the dissertation, to extend supervisee autonomy at a central stage, and to distance supervisors further from the written output at a final stage in the process. This study questions whether this approach is satisfactory either in an institutional context where the supervisor is also first marker of work they may have shaped substantially, or as a pedagogic approach to developing research skills.
\end{abstract}

Undergraduate research; dissertation; research-teaching link; research supervision 


\section{The challenge of achieving transparency in undergraduate honours-level dissertation supervision Introduction}

The experiences of research supervisors and their supervisees in higher education has been examined most thoroughly in the context of doctoral and masters-level research degrees. This is unsurprising, given the levels of individual and institutional investment involved, and the criticality of the supervisory relationship and supervision process to overall outcome (Tight 2012). It is generally accepted that the process of postgraduate research supervision is complex, and varies over time as well as within each supervisory setting (Acker 2001; Harding-De-Kam, Hamilton and Loyd 2012; Boehe 2016). The challenge of theorising supervisory practice arises in part from diverse purposes attributed to doctoral study (Brew and Peseta 2009), and also from the multiple and intersecting layers of influence - external, sectoral, institutional, disciplinary (Healey, Lannin, Stibbe and Derounian 2013), personal (Brew and Peseta 2009), and cultural (Grant and Manathunga 2011).

\section{Approaches to supervision in doctoral research}

Within this complex context, supervision is constructed as a dynamic relationship informed by a combination of differing and sometimes competing objectives, experience and expectations among the individuals involved (Bingham and Duran-Palma 2014). The supervisory process is variably perceived by supervisors as either teaching or research practice (Kyvik and Smeby 1994; Johnson et al. 2000). The impacts of a power imbalance generated through the interplay of disciplinary and structural 'authority' in the supervisory role (Grant and Graham 1999), and those of differing student and supervisor conceptions of research process and purpose (Brew 2001; Meyer et al 2005; Kiley and Mullins 2005) generate further dimensions to the experience of both supervisors and their supervisees. Disciplinary differences impact directly on the format as well as the ethos of the supervisory relationship. For example, Egan et al. (2009) compare doctoral student experiences of the paired supervisory relationships common to the humanities and social science with those of the more consistently supportive team-based research model characteristic of research in science subjects. They find the former to be potentially productive but rather distant and formal, a finding supported by Noy and Ray's (2012) examination of the systematic supervisory disadvantage experienced by black female supervisees. From this recognition of complexity and variety, a series of explanatory typologies (e.g. Sambrook et al. 2008; Harding-De-Kam 2012; and Acker 2001) identify a range of approaches and actions required of 'an experienced academic...able to move through and to' different supervisory models (Lee 2012, 12).

While particular value is found in certain approaches (e.g. Styles and Radloff 2001), the research field does not yield decisive normative judgements about supervisory practice. Variability and change are accepted as inherent in a dynamic and multifaceted supervisory relationship that 'cannot be made entirely predictable or homogenised' (Acker 2001, 76). This suggests to Lee $(2009,132)$ a 'need for combining approaches' in individual practice rather than defining a single preferred model. Brew and Peseta $(2009,136)$ note that supervisory experience itself can present a barrier to an individual supervisor's development of a fully 
theorised understanding of the complexity of their role. Unexamined assumptions can become ingrained in practice, at the expense of a fully formed repertoire of responses grounded in 'an overarching theoretical approach to supervision.' Research into the supervisory role within postgraduate research studies has yielded actionable insights rather than, as yet, a single operational model with sufficient explanatory power to achieve normative authority. The range of potential approaches and relationships emerging from the available typologies does, however, point to the importance of both reflexive individual practice and operational transparency within the supervisory dynamic, as both parties seek to form and manage their roles in an evolving professional relationship (Sambrook et al 2008).

\section{The role of the undergraduate honours dissertation}

The current study focuses on the honours dissertation ${ }^{1}$ as a compulsory or optional component within the final stage of a UK Bachelor's degree [QAA 2014]). Although some studies of doctoral supervision (e.g. Lee and Green 2009), identify their findings as relevant beyond the specific conditions of postgraduatelevel research, considerably less direct research attention has been paid overall to the characteristics and dynamics of supervision within the honours dissertation as identified here, or to the 'minor thesis' that forms part of many taught masters degrees (Drennan and Clarke 2009; Stelma and Fay 2014). Both constitute important stages in the development of research and enquiry skills, recognised as a more or less integrated developmental experience by students themselves (Bowers and Paramewswarana 2013).

The UK undergraduate dissertation is often conducted in a tightly time-constrained process either as a final intensive block of study, or in parallel with other equally award-critical studies (see Schweinsberg and McManus 2006, 52; and also Brew [2013] and Zimbardi and Myatt [2014] on the different structural position of the Australian honours dissertation, by way of contrast). With this positioning, questions around the balance between developmental purpose and immediate outcome become particularly significant. Much of the research into the dissertation component of taught undergraduate programmes focuses on the value and purpose of the dissertation experience, both as a summative expression of critical outcomes of higher education, and a vehicle for learner development in relation to those outcomes within the context of a broader link between research and teaching (Brew 2013; Beckman and Hensel 2009). As with its counterpart, the Australian honours programme (Wisker 2018), it is assigned 'two quite specific roles: as a "rounding off" of an undergraduate award, and as training for further research.' (Kiley et al. 2009, 23). The combination of immediate and developmental value in the honours dissertation reflects a wellestablished formulation of student interest in the research-teaching nexus more broadly, comprising their immediate academic outcome, their subject interest, and their graduate prospects (Elton $(2001,47)$. The value of the UK honours dissertation has been evaluated differently in different disciplines (see, for example, Watson [1983] on Business; Stefani et al. [1997] and Hunter et al. [2006] on its role in science subjects; Cuthbert et al. [2012] on Sociology; and Griffiths [2004] on the built environment). Yet there is

\footnotetext{
${ }^{1}$ The term 'dissertation' is used throughout this study, although the terms 'project' and 'thesis' are also in regular current use to refer to course components of similar level and dimension.
} 
an overall acceptance that the undergraduate dissertation is a curriculum item of particular value in a (super)-complex and unstable knowledge environment (Barnett 2000) in which 'the basic assumption of uncertainty changes both the process and source of knowledge substantially’ (Baxter-Magolda 1992, 137). Research skills are deemed essential to continued currency through lifelong learning (Shaw et al. 2013, 712). Within this context, ambitious claims are made for the undergraduate dissertation experience, as a stepping stone towards Willison's 'unbounded research' capability (see Wisker 2018), that is 'pivotal in shaping students' future career trajectories' as knowledge producers (Ozay 2012, 462). The learner experience of the undergraduate dissertation as a capstone component of study (Hauhart and Grahe 2015) is a consistent feature of pedagogic strategies proposed to provide a progressively developed student understanding 'of the role of research in their disciplines (or interdisciplines)' (Jenkins et al. 2003).

The fundamental requirements of this ambitious goal are well recognised in the research base. In summary, the developmental trajectory, in which the dissertation forms a significant threshold stage, combines the development of knowledge and knowledge structures with that of an understanding of the nature of knowledge and the processes by which it is created (Baxter-Magolda 1999, 6). This requires the participation of a 'self-regulated student' who is able 'to reflect on goals, strategies, beliefs and outcomes, and regulate these components through metacognitive processes' (Styles and Radloff 2001, 99). Current research acknowledges that supervisory practice differs between supervisors, and in some cases within the repertoire of a single supervisor, and recognizes that all available approaches are not equally effective in every circumstance (Brew and Peseta 2009). However, given the emphasis on both the immediate and the longer term value of an effective undergraduate dissertation experience, it is important to establish as clearly as possible the dynamics of a supervisory process capable of supporting both at the same time. This includes consideration of how the supervisee is positioned within a structurally imbalanced supervisory relationship to develop the self-regulation on which the research value of the dissertation experience depends.

\section{The supervisory role at undergraduate level}

Healey et al (2010) note, in their study of undergraduate student perspectives on research, that 'the students' experiences of research within their learning were often significantly shaped by the relationship with their dissertation tutor and final-year lecturers. The contextual constraints of the UK undergraduate dissertation may limit the potential of the supervisory process to a significantly 'functionalist' approach to academic supervision (Lee 2012) and to mentoring more broadly (Darwin 2000), in contrast with the broader range of approaches afforded by the extended time period available at the more advanced doctoral stage. It is difficult, for example, to see how the types of activity proposed by Lee (2012) could be operationalized within the more limited framework of an undergraduate project experience. Academic supervisors must customize supervisory practice to the circumstances of undergraduate research and the needs of the undergraduate supervisee. A relatively rapid supervisor judgement of potential, followed by a relatively truncated period of response, is required here, rather than the more expansive and personal dynamics of the doctoral supervision process (Wright et al. 2007). Describing the tension between 'dialogue' and 
"instruction" in teaching practice more generally, Renshaw $(2004,10)$ notes that "effective teachers have learned how to perform in this contradictory space to both follow and lead, to be both responsive and directive, to require both independence and receptiveness of learners. Within the undergraduate dissertation, it is expected that a supervisor 'respects autonomy and facilitates scholarly independence' (Mackinnon 2007, 402) while also promoting the immediate qualification interests of the student. Both must be achieved within a process that cannot 'be made entirely predictable or homogenized' (Acker 2001, 76) any more than can doctoral supervision (Boehe 2016).

Additional complicating factors are also acknowledged in the research literature. Students have differing interpretations of the same process (Levy and Petrulis 2012, 91) and there are distinct disciplinary differences within supervisory practice (Zimbardi and Myatt 2014). Academics' conceptions of what constitutes a good supervisee also vary (Kiley and Mullins 2005). And yet, although the challenges for both parties within the process are well documented (e.g. Todd et al 2006), Schweinsberg and McManus (2006) note the low priority often given to the development of supervisory skills for undergraduate work. Within this context, the current study examines how, in the practical and pedagogic context of undergraduate study, supervisors identify and respond to student needs and expectations in ways that respond both to the immediate award interests, and the longer-term developmental interests, of their supervisees.

\section{Method}

To examine issues of supervisory power and role in undergraduate dissertation supervision, a qualitative study was conducted on data collected from two post-' 92 UK higher education institutions in which the curricular basis of supervisory practice was broadly equivalent. Both institutions offered individually supervised honours dissertations as core (rather than optional) curriculum components carrying $40 \%$ - 50\% of the academic credit associated with the honours stage (level 6 in the UK Framework for Higher Education Qualifications) of undergraduate social science programmes. In both institutions a prescribed pattern of supervision specified bi-weekly supervisory sessions over a two-semester period, with a total supervisory time allocation across all subjects of between 15 and 18 hours per student (following introductory plenary lectures), with a 'normal' expectation of fortnightly meetings, adapted to individual circumstance by agreement. In both institutions, supervisors operated as first markers of their supervisees' submissions, within a double-blind two-marker process with specified requirements for the involvement of a third marker in the case of grading difference beyond a specified margin.

Ethical approval for this research and its methodology was obtained from the Research Ethics Committees of each institution prior to data collection. Email invitations to participate were issued to all current honours dissertation supervisors in the subjects identified in Table 1, requesting their participation on the basis of a minimum of three years' experience in the supervision of honours dissertations. Interviews were conducted with all but four volunteers (the responsibilities of the four had changed since the supervisor invitation lists were compiled and they were no longer supervising undergraduate dissertations). In total, twenty 
individual interviews were conducted with honours dissertation supervisors with at least three years' supervisory experience, and with the overall interviewee profile as shown in Table 1. Interviewee consent to the recording and use of data was obtained in writing prior to interview in all cases.

[Table 1 near here]

Within a semi-structured interview format, supervisors were invited to describe in detail their characteristic approach to the supervisory process and their perceptions of the characteristics of good supervisors and supervisees. Interviews, each of twenty-five to thirty minutes' duration, were recorded and then transcribed in full. After initial framing, to focus the interview on current practice in undergraduate dissertation supervision, the following five questions were used to structure each interview, with the order and exact wording varied to facilitate fluency response and minimise the imposition of structure by the interviewer:

What is your approach to supervising?

(How) does that approach vary?

(How) does your approach change (in each supervisory relationship)?

What are the challenges of supervision?

Why do you take the approach you do?

Additional prompts were restricted to requests for clarification, elaboration and operationalisation, avoiding additional probing that might lead to a focus on self-justification. This approach allowed the interviewees' own priorities and supervisory process structures to emerge through the detail of their responses.

Interviews were analysed using a grounded theoretical approach to the micro-analysis of detailed instances of codes in use. This approach was adopted in order to reveal individual practices and attitudes within the formal and documented supervisory process. The use of a 'prefabricated' set of codes (Miles and Huberman 1994, 58) might reinforce formal concepts in general academic use to describe supervision, and miss the opportunity 'to uncover data that otherwise might be overlooked' (Glaser 1978, 39). Provisional conceptions and connections emerging through this process of open coding were then recoded thematically to identify patterns of supervisor decision and action observable across the transcript set.

\section{Findings}

\section{Supervisor perceptions of research and the undergraduate dissertation}

A number of preliminary themes emerge from the initial coding process, reflecting the relative priority for individual supervisors of the product and process of dissertation study, and of the immediate credential value and the longer term developmental role of the experience. For some supervisors, the dissertation process is a heuristic and relatively unconstrained process that is driven by student interest and 'not set in stone'. Other accounts suggest a more prescribed process in which students learn to adjust their aspirations and methods to requirements that reflect the demands of disciplinary methodology and/or its practical application, within a process envisaged as a prescribed 'path' or 'road'. A cross-cutting distinction emerges 
between those supervisors who conceptualise the dissertation process as an integrated task of research and document production, and those who identify research and the production of a final written outcome as tasks presenting different and sometimes conflicting priorities. For one supervisor, for example, the development of expertise by a student who in the end 'should be the expert in the department apart from me' runs in parallel with the requirement for progress against a timescale to deliver "2,000 words before Christmas" (supervisor 4). For another supervisor, recalling their satisfaction at being presented with a 'massively ambitious idea' or a 'fabulous topic', the awareness of formal contextual requirements remains such that the parameters of the institutional requirement determine 'a time to add a straightjacket' (supervisor 11). The potential for discrepant student performance across the two dimensions - subject and product - is acknowledged by one interviewee:

and there is the case of a 'really good student...doing a really big interesting project...but her write-up was one of the worst things that I've ever seen' (supervisor 17)

These differences do not appear to be correlated with subject area or with level of supervisory experience, but do appear to be correlated with timing differences in supervisor expectations of finalised dissertation structure as reflected in Figure 1 (below), in that those supervisors who describe undergraduate research as an heuristic process express relatively delayed expectations of structural finality in the finished dissertation product. These differences appear to reflect and confirm the variability in supervisor conceptions of research, and of the nature and value of undergraduate research already established in the research literature (e.g. Brew 2001; Kiley and Mullins 2005).

The exercise of supervisory direction is not uniform among supervisors or even within an individual supervisor's practice. Where there is no 'fabulous topic' to offer an early signals commitment and/or ability, information to guide the supervisor's work emerges gradually. The cues come from body language, 'the look in their eyes' and messages arising from tone and attitude. They come from students asking 'the right questions' and from their arrival at supervisory sessions with 'specific things' to ask, based on the work already done. It is not just ability but also willingness and commitment - what they are 'willing to do'. And in response to the emergence of such cues, the supervisor's role may well involve 'leading them without their realising' (supervisor 3). The dissertation process is, in part, one of persuasion that gets supervisees 'on board' while maintaining their conviction of their autonomy that encourages them to continue. This includes the most capable students, who 'start to realise what they are capable of' and are pushed within the supervisory process until, in one case, they 'realised that actually she was capable of so much more than she even realised' (supervisor 15).

\section{Distancing as a means of managing ethical risk}

A consistently sustained distinction within supervisor accounts identifies and demarcates the limits and the timing of a supervisor's dual role, as tutor and as gatekeeper. A total of 14 interviewees identify their final role as distinct, in their view, from their earlier role in the supervisory process. Six interviewees describe their practice of reducing their level of detailed comment and input at an identified final stage in the 
dissertation process. Four of these cases include an explicit reference to a perceived need to distance themselves from the grade outcome. In a further 8 cases, while there is no explicit identification of a final stage, items such as 'sections', 'write-ups', and 'early drafts' are identified as legitimate objectives of detailed review and comment by supervisors. Full chapters, finalised chapters, and sets of chapters available only at a late stage in their described dissertation process - receive only light-touch review, or comment on matters of style and format identified as somewhat distinct from the research task. In a further three cases, a clear distinction is made between a core supervisory stage, and a final supervisory stage, through the use of a timing reference without any role differentiation.

Supervisors may intervene directly in a student's work at various points, and may even describe themselves as teaching some aspects of the overall requirements. Yet they may also be, and are in both institutions studied here, responsible for the first-marking of their students' dissertations. It is in the context of the ethical challenges this creates for supervisors, that their efforts to distance themselves from the final product of their own guidance should be seen. One interviewee describes how he becomes aware of the extent to which his guidance has been acted upon only on receipt of the final submission. Another describes their surprise, in some cases, at the outcome of their supervisory efforts, and one supervisor makes direct reference to the challenge of their dual role as supervisor and as a marker grading, in part, their own effectiveness as supervisor. The separation of developmental process from final product may represent the mean by which the ethical integrity and practical coherence of the supervisor's role as both advisor and marker are sustained. In-process supervision is separated from a final production stage (stage 3, in Table 2 [below]), as a means of allowing the finalization, marking and grading processes to be conducted separately from supervision. Supervisors may construct the boundary at different stages within both the process and therefore different points within the overall dissertation timeframe, but a significant majority of supervisors studied here construct an identifiable 'final stage' before that of formal assessment and grading. There is no indication in their accounts that this boundary is made explicit to supervisees, or that their individual practice in setting it is understood by individual supervisors as a variable within supervisory practice that is of significant impact on the supervisees' experience of the dissertation or the transparency of its operation.

\section{Supervision as a staged process}

Across the data, a further boundary is drawn by some supervisors between two identifiable stages preceding that final stage of the dissertation process. Data from those supervisors who do not draw this distinction explicitly contain no contra-indications, but are characterized by a predominating focus on variations in supervisory practice that respond to perceived student differences. Figure 1 (below) defines the three stages emerging from the data.

[Figure 1 near here]

Within this broad outline, two accounts indicate that subject selection might be considered a stage preceding stage 1 of the dissertation process, and there is evident variability in the timing, across accounts, of the 
emergence of a final dissertation structure. There are also evident differences in supervisory practice in relation to the review of draft content within stages 1 and (particularly) 2 . While all supervisors identify the review of draft material as part of their supervisory remit, some, but not all, include reviewing draft data analysis within the supervisory task. There are significant differences (not correlated with subject or experience) between supervisor views of the appropriate unit of review. Some accounts describe reviewing draft chapters, and others only 'sections' and 'task write-ups' of smaller dimension. For five supervisors, varying this aspect of supervision forms part of their flexible response to varying supervisee needs. Thus the transition from stage 2 to stage 3 is variably achieved, with potential implications for consistency of supervisee experience and understanding of the process. However, while the equity of these variations in practice across supervisors and supervisory relationships in respect of content review is a matter for consideration, the evidence that a transition is made between two defined stages ( 2 and 3 ) between which a supervisor changes role, from guide to grader, remains as shown in Table 2 (below).

In parallel with the distinction between the final stage and earlier stages, the first two stages (stages 1 and 2 in Figure 1 and Table 2) are marked by a combination of temporal reference and specific references to a 'change' in supervisory role. Supervisors refer directly to 'stages', or the 'next job', and an early sub-task being 'completed' or 'done', and identify material changes in operating mode at each stage ( e.g. 'then I become a coach'; 'after that I can let the student....'; ). These features of supervisory descriptions of their role point clearly to two distinct phases in the pre-final period (i.e. prior to stage 3 ) in eleven of the twenty interviews. These stages are distinguished by changes in supervisory role and practice and the dynamics of the supervisor/supervisee relationship, and are summarized in Table 2.

[Table 2 hear here]

Within this multi-stage process, shifts occur in the role of the supervisor, and consequentially in the supervisor's and supervisee's relative control of the process. At the initial stage, the supervisor is more openly instrumental in determining the direction and scope of the work to be completed. As one supervisor put it, this is the point at which they 'put them [supervisees] down a road' on which they will succeed, and ... shape the process within 'the sphere of what I would expect you [the supervisee] to know' (supervisor 8). Where supervisees offer opportunities for early supervisor intervention in research design, supervisors' prospects for exercising their responsibility to shape the dissertation experience are particularly strong. The means by which they do this are far from transparent to their supervisees. While some supervisors claim a 'clean sheet' approach in which 'everyone starts with a first as a target', for others, prior knowledge of a student may be influential in determining what is 'appropriate for them'. Among supervisors who distinguish prior achievement explicitly from emerging dissertation potential, there may nonetheless be early evidence of capability or 'sparkle' in the dissertation that influences their intervention at this critical stage:

'those that I think are first class students I'm happy to put them down a road that's much more difficult and challenge them whereas some - I would never limit or constrain them - but I might say rather than 
making it so complicated that it's just going to be a mess at the end perhaps you could simplify it in this sort of respect.' (supervisor 10)

Following this preliminary stage, and prior to the emergence of a 'product' from which the supervisor separates themselves quite deliberately, an in-process stage precedes the emergence of a (near)-final product. This middle period is identified explicitly in the data through direct temporal reference, and also through the identification of what was termed 'the research stage', 'the research proper', and 'the main part of the work'. It is at this stage that 'it [the process] becomes student-led'. And here, more than in either of the other two stages, supervisors describe their approaches as responsive primarily to their understandings of individual student need and preference. Two axes of variability in supervisor intervention emerge - the first identifying frequency of intervention and the second degrees of direction within that intervention. Some students require 'more attention' and 'more frequent checking' in a process identified as 'handholding'. Supervisors 'push' and 'nudge' students identified as falling behind the pace in the delivery or quality of their work, and are more or less prescriptive in their interventions according to a perceived need to get them '(back) on track'. While a 'really first class student' needs little prompting, for others 'constant adjustment' is needed.

While the initial stage of supervision may be substantively directive on the part of supervisors, it is in what supervisors identify as a central stage in the dissertation process that the direction appears to be implicit in supervisory action and not available to supervisees as a basis for the exercise of independent choice. The supervisors interviewed for this study construct a process in which student independence operates predominently in the work done between rather than within supervisory meetings. It is a feature of individual study, with supervisory sessions providing periodic checkpoints. Intensive and more protracted handholding, and/or more direct intervention at all stages may be required at more frequent checkpoints for students identified as 'weak' or 'less engaged'. Supervisor effort is not, however, straightforwardly correlated with student ability, since supervisors refer both to students who 'need' more assistance than others and at the same time reveal the extent of support they are prepared to put into the work of the 'very best'. A student's decision to engage proactively more or less fully with the supervision offer is, in part, a facet of that independence, but the exercise of that independence is located in supervisor accounts of the overall process as a feature of work in follow-up and response to supervisor intervention rather than as a feature of direct supervisory interaction. The language of steering, leading, guiding and pushing is used throughout the interviews to describe the role of the supervisor within a more or less precisely articulated central phase of the dissertation process. It is used uncritically, and without any suggestion that the choice or operation of these roles should constitute an explicit component of the formation process.

\section{Discussion}

The construction by supervisors of the overall process as a series of definable stages reveals their approaches to managing conflicting aspects of their complex supervisory role. They provide coaching in research development, while at the same time ensuring the immediate achievement of award-critical credit. 
None of the supervisor accounts examined in this study makes reference to the exposure of these shifts in the supervisory dynamic, or their operation of authority within it, in ways that would enable the selfdirection and prolonged engagement through which a supervisee achieves and maintains personal ownership of what is a complex, unstructured, and largely novel research task. And yet this ownership is critical, whether we formulate this final stage of the research-teaching link primarily as the construction of personal, rather than public, new knowledge (Levy and Petrulis 2012), or as enabling graduates to become enquirers in their prospective practice fields (Brew 2013), by developing the 'ability to question received knowledge and scrutinise [their] own values and assumptions' (Guerin et al. 2015, 10), and by thinking 'in innovative ways within their disciplines' (Shaw, Holbrook, and Bourke, 2013, 724). The limitations on supervisory practice created by exogenous variables such as institutional structures, and the abilities of individual students are recognised (Garrison (2016). Challenges in supervisory practice arising from the weight of expectation around the undergraduate dissertation remain largely unacknowledged and therefore unresolved. How can the tensions inherent in the role of undergraduate dissertation as both capstone (to the undergraduate study programme and its outcome) and milestone (on the route to research independence) be resolved so that these complex and sometimes conflicting expectations are achieved? And what are the parameters of supervisory practice at undergraduate level capable of securing them?

There are significant differences between the processes of doctoral and undergraduate research, and these limit the potential implementation at undergraduate level of recommendations arising from studies of doctoral supervision. And the research base in doctoral supervision contains its own challenges and complexities. Doloriert et al. $(2012,746)$ envisage an empowering and facilitative supervisory role that supports supervisee agency and authority within that 'dynamic form of HRD practice' that is doctoral supervision. Yet they define the supervisory role unproblematically as to 'steer, guide and support' (Doloriert et al. 2012, 733). The standard doctoral supervision metaphors of discipleship and apprenticeship (Lee and Green 2009) are themselves problematic as routes to authorial independence, both conveying dependence and a degree of power-based constraint of the novice. Moving away from these metaphorical models might involve either explicit acknowledgement of doctoral supervision as 'teaching' (Bruce and Stoodley 2013), or the identification of supervisory practices that allow supervisors to operate without compromise in the 'dilemmatic space' at the intersection of task objective, individual student competence and institutional context (Vereijken et al. 2018, 524). In any case, transparency is essential to making mutual expectations explicit from the outset (Harding-De-Kam et al. 2012). The hidden role of the supervisor in offering differential levels of support and direction is well documented (e.g. Evans 2016, 28), and is perhaps most problematic where individual agency is required to generate collective efficacy in an increasingly common team model of supervision (Robertson 2019, 16-17). Despite these challenges, the more robust research base around doctoral supervision provides a valuable starting point for consideration of issues common to supervision at both levels. Indeed, structural differences between the two contexts particularly the relatively novice status of undergraduate researchers, as well as the more compressed timeframe of the undergraduate dissertation, and the more limited supervisory resource available -make the fundamental concerns and findings within the doctoral research base more, rather than less, relevant to supervisory practice at undergraduate level. 
The particular challenge of developing independent learners in an undergraduate population of variable aptitude for the task is just one of the potential value conflicts academic staff must confront (Skelton 2012). The imbalance of experience and expertise within the supervisory relationship puts supervisors in a powerful position to evaluate and act differentially on indications of student ability and/or commitment. The current study has identified tensions within the supervisory process, arising from complex expectations of the dissertation experience. Developing and maintaining students' conviction of independence and accountability throughout their work is recognised by supervisors as a feature of their practice. Yet their immediate responsibility is to enable completion and achievement. The level of supervisory control required to ensure this primary aim is achieved appears from supervisor accounts of their practice to limit the transparency with which they operate as supervisors. Taking the individual learner's 'interests and capabilities' as the starting point for pedagogic choice (Brew 2013, 617), does not mean that a supervisor's approach is necessarily transparent to the learner. The balance between a learner's multiple interests in completing the dissertation appears, therefore, to be a matter for negotiation only within the mind of the individual supervisor, and not an explicit matter of supervisor-supervisee consideration.

This qualitative analysis of supervisors' own accounts of their practice confirms the supervisory process as multi-stage and non-uniform. It is likely to require 'a certain amount of handholding' at the outset, and more or less intensive monitoring at the final stage when, for in some cases, 'most of your work is done', to deliver an adequate final product. Across this process, some students are identified as needing more assistance than others, and a number of interviewees described their willingness to go further than the minimum requirement for students showing high levels of engagement or early promise. The complexity of the supervisory function is also confirmed. Supervisors agonise over their responsibility to do the best for each supervisee. They distinguish their role in reviewing a near-to-final product from their closer engagement with the process by which that product is produced. This distinction is central to the ethical balance struck by supervisors between the roles of teacher and gatekeeper. But the evidence of this study suggests that experienced and apparently effective supervisory practice may itself undermine that quest through its less than transparent efforts to manage it. This study finds that supervisors may operationalize a staged approach to the supervisory process that is not recognized in either its detailed dynamics or its potential impact, in current research. Supervisors' implicit operation of a start-up stage, an in-process stage, and a final stage in which the dissertation as product is visible - stages in which they take on different, and in some cases variable, roles in relation to supervisee autonomy - point to a systemic approach to the management of a complex supervisory task.

\section{Conclusion and limitations}

This study has identified features in the supervision of undergraduate dissertations that point to supervisors' exercise of significant and varying levels of direction at control at different stages within the dissertation process. Supervisors themselves appear to construct these stages, more or less distinctly in individual cases, either directly by referring to temporal stages in the process, or indirectly through variations in their own 
defined roles as supervisors. The substantial exercise of student independence seems, in their accounts, to start in the second of these three stages, and a particular distance between the supervisor and a student's final dissertation output emerges at the third.

To allow supervisor constructions of the supervisory process to emerge without interviewer interference, this study did not probe further the understandings of those supervisors from whom recognition of this staged process did not emerge unprompted, and a further study to confirm these emerging concepts and categories would be useful. Neither did this study probe further at interview a number of aspects of supervisory practice that might usefully be examined further as potential correlates of this approach, such as individual supervisors' conceptions of research, and of research supervision. Further study using more granular categorisations of research activity and supervisory experience within supervisor profiles might refine these findings further. Examining whether characterisations of the supervisory process differ significant between this group and a comparator group in which supervisors are not also subsequently involved in the marking process might yield important implications for institutional marking practices. And a further line of enquiry might explore student understandings of this staged approach to supervisory process, to identify the extent to which students recognise and actively work with their supervisors' varying degrees of direction.

The obligations of supervisor and supervisee within the learning process are reciprocal (Regan 2012). Roberts and Seaman $(2018,36)$, in findings that include the potential for supervisors to dominate the process of undergraduate research supervision, identify it as 'a negotiated practice between supervisor and students' in which the relationship itself, as well as the project, develops as part of the learning process. For this to happen, supervisees and supervisors must work with a full understanding of the nature each other's role in the supervisory process. Supervisees must also be in a position to identify the operation of the lecturer's role, so that they can engage effectively with it in ways that develop their own autonomy and agency in relation to the task at hand. The constraint to this developmental drive at the undergraduate honours dissertation stage is therefore not (only) that it is a complex function (Brockbank and McGill 2012, 305-6), or that it is, for a supervisee, an 'iterative movement between control and autonomy' (Wisker 2018, 4), but also, and critically, the fact that the supervisory process itself is not transparent. The current findings are significant in that they are somewhat at odds with the more straightforward characterisations of supervisory practice in research literature that assume students undertaking this, usually their most demanding and independent undergraduate assignment, operate with new and significant levels of autonomy in their research.

At doctoral level also, Nordentoft et al. (2013) suggest that the one-to-one power relationship is problematic and could be redesigned through collective academic supervision. Bingham and Duran-Palma, (2014) propose (again in relation to doctoral supervision) the lens of a pluralist perspective on employment relations. This sets supervisors the task of maintaining practices that surface the values, beliefs and 
expectations of both parties involved, recognising inherent conflicts of interest and power differentials, balancing competing interests and engaging consistently with the challenge of securing supervisee input to decision making. Alternatively, the requirements of an effective client relationship have been suggested for transfer to supervisory practice (Mackinnon 2004). Adapting these, or other available models, to the dynamic of dissertations supervision will not in itself achieve a practice that fully supports researcher development. For this to happen, the selected model will need to be negotiated transparently by supervisor and supervisee on the basis of an explicit and shared recognition of roles and responsibilities, underpinned by transparent practice. That recognition, and its operation in practice, might usefully be recorded and monitored within a learning agreement, or through a developmental record maintained by the student. The particular structures and practices of dissertation supervision identified in this study may arise from supervisors' well-intentioned efforts to meet the complex and interacting expectations of students, academic institutions and subject fields. They may also be influenced by supervisors' concern to fulfil their responsibility to support students at a critical moment in their academic programmes while also maintaining an appropriate distance from work they must also judge and grade. This latter point might be resolved by maintaining a clear distinction between the two roles, so that the practice in some HEIs of requiring supervisors to operate as markers of the research they have supervised is simply stopped. But a broader reexamination of supervisory practice is also indicated, if that practice is to support fully the development of researcher independence as an important aspect of the undergraduate dissertation experience. 
Table 1. Interviewee profile

\begin{tabular}{|l|c|c|c|c|}
\hline Subject area & Female & Male & \multicolumn{2}{|c|}{ Supervisory experience } \\
\cline { 3 - 5 } & & & $3-5$ years & 6 years or more \\
\hline General Business (HEI 1) & 3 & 5 & 5 & 4 \\
\hline General Business (HEI 2) & & 1 & & 1 \\
\hline Law (HEI 1) & 2 & 1 & & 2 \\
\hline Law (HEI 2) & & 0 & 1 & 1 \\
\hline Accounting and Finance (HEI 1) & 0 & 1 & & 2 \\
\hline Accounting and Finance (HEI 2) & 1 & 1 & & \\
\hline Psychology (HEI 1) & 1 & 0 & & \\
\hline Psychology (HEI 2) & 0 & 2 & & \\
\hline Sports studies (HEI 1) & & 1 & & \\
\hline Sports studies (HEI 2) & & & & \\
\hline
\end{tabular}

Table 2. Supervisor identification of stages in the supervision process through temporal reference and explicit role distinctions between stages

\begin{tabular}{|c|c|c|c|c|}
\hline & $\begin{array}{l}\text { Temporal } \\
\text { reference } \\
\text { identifies } \\
\text { stages } 1 \& 2\end{array}$ & $\begin{array}{l}\text { Distinct } \\
\text { roles } \\
\text { described } \\
\text { at stages } 1 \\
\& 2\end{array}$ & $\begin{array}{l}\text { Temporal } \\
\text { reference } \\
\text { identifies } \\
\text { a final } \\
\text { stage } \\
\text { (stage 3) }\end{array}$ & $\begin{array}{l}\text { Distinct role } \\
\text { described at stage } 3\end{array}$ \\
\hline $\begin{array}{l}\text { Accounts } \\
\text { with bot } \\
\text { reference } \\
\text { types } \\
\text { included }\end{array}$ & & & & 8 \\
\hline $\begin{array}{l}\text { Accounts } \\
\text { including } \\
\text { one } \\
\text { reference } \\
\text { type }\end{array}$ & 4 & 2 & 3 & 6 \\
\hline
\end{tabular}


Figure 1: Stages of supervisory practice

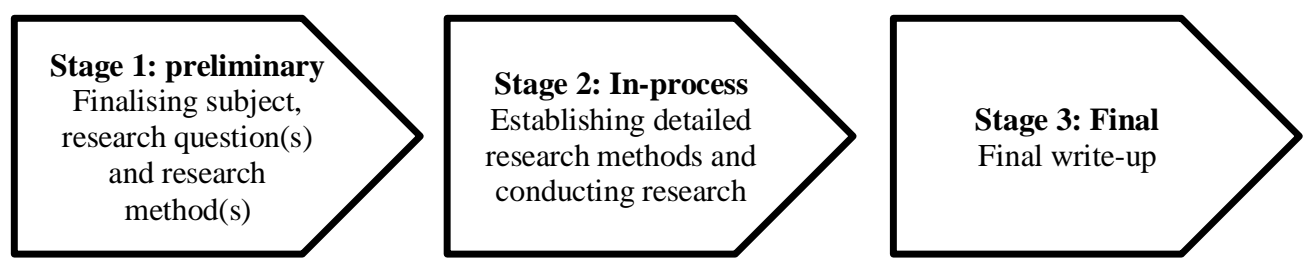

Determining structure and organisation of material 


\section{References}

Acker, S. 2001. "The hidden curriculum of dissertation advising." In The hidden curriculum in higher education, edited by E. Margolis, 61-77. New York: Routledge.

Barnett, R. 2000. “Supercomplexity and the curriculum.” Studies in Higher Education 25: 255-265.

Baxter Magolda, M. 1992. Knowing and reasoning in college: Gender-related patterns in students' intellectual development. San Francisco, CA, US: Jossey-Bass.

Baxter-Magolda, M. 1999. Creating contexts for learning and self-authorship. Nashville, Texas: Vanderbilt University Press.

Beckman, M. and N. Hensel. 2009. "Making explicit the implicit: Defining undergraduate research." Council for Undergraduate Research Quarterly 29: 40-44.

Bingham, C., and F. Duran-Palma. 2014. "Rethinking research supervision: Some reflections from the field of employment relations." Teaching in Higher Education 19 (1): 78--89.

Boehe, D. 2016. “Supervisory styles: A contingency framework." Studies in Higher Education 41 (3): $399-414$

Bowers, J., and A. Parameswarana. 2013. "Differentiating undergraduate research." Teaching in Higher Education 18 (5): 453-464.

Brew, A. 2001. "Conceptions of Research: A phenomenographic study." Studies in Higher Education 26 (3): 271-285.

Brew, A. 2013. "Understanding the scope of undergraduate research: A framework for curricular and pedagogical decision-making." Higher Education 66 (5): 603-18.

Brew, A., and T. Peseta. 2009." Supervision development and recognition in reflexive space.” In Changing practices of doctoral education edited by D. Boud and A. Lee, 126 -139. Oxon: Routledge.

Brockbank, A, and I. McGill. 2012. Facilitating reflective learning: Coaching, mentoring and supervision. 2nd ed. London: Kogan Page.

Bruce, C. and I. Stoodley. 2013. "Experiencing higher degree research supervision as teaching." Studies in Higher Education 38 (2):226-241.

Cuthbert, D., D, Arunachalam, and L. Dunja. 2012. "'It feels more important that other classes I have done': An 'authentic' undergraduate research experience in Sociology." Studies in Higher Education 37 (2): $129-42$.

Darwin, A. 2000. "Critical reflections on mentoring in work settings." Adult Education 50 (3): 197--211.

Doloriert, C., S. Sambrook, and J. Stewart. 2012. "Power and Emotion in Doctoral Supervision: Implications for HRD.” European Journal of Training and Development 36 (7): 732-750.

Drennan, J., and M. Clarke, M. 2009) "Coursework Master's Programmes: The Student's Experience of Research and Research Supervision.” Studies in Higher Education 34 (5): 483-500. 
Egan, R., D. Stockley, B. Brouwer, D. Tripp, and N. Stechyson. 2009. "Relationships between area of academic concentration, supervisory style, student needs and best practices." Studies in Higher Education 34 (3): $337-45$.

Elton, L. 2001. "Research and Teaching: Conditions for a positive link." Teaching in Higher Education 6(1): 43-56.

Evans, J. 2016. How to be a researcher: A strategic guide for academic success. London: Routledge.

Garrison, D. 2016. Thinking collaboratively: Learning in a community of inquiry. New York: Routledge.

Glaser, P. 1978. Theoretical sensitivity: Advances in the methodology of grounded theory. California: The Sociology Press.

Grant, B. and A. Graham. 1999. "Naming the Game: Reconstructing graduate supervision.” Teaching in Higher Education 4 (1): 77-89.

Grant, B. and C. Manathunga. 2011. "Supervision and Cultural Difference: Rethinking Institutional Pedagogies." Innovations in Education and Teaching International 48 (4): 351-354.

Griffiths, R. 2004. "Knowledge production and the research-teaching nexus: The case of the built environment disciplines." Studies in Higher education 29 (6): 709-726.

Guerin, C., H. Kerr, H. and I. Green. 2014.” Supervision pedagogies: narratives from the field." Teaching in Higher Education 20 (1): 107-118.

Harding-DeKam, J., B. Hamilton, and S. Loyd. 2012. "The Hidden Curriculum of Doctoral Advising." NACADA Journal 32 (2): 5-16.

Hauhart, R., and J. Grahe. 2015. Designing and teaching undergraduate capstone courses. New Jersey: John Wiley and Sons.

Healey, M., F. Jordan, B. Pell, and C. Short. 2010. "The research-teaching nexus: A case study of students' awareness, experiences and perceptions of research." Innovations in Education and Teaching International 47 (2): 235-246.

Healey, M., L. Lannin, A. Stibbe, and J. Derounian. 2013. Developing and enhancing undergraduate final-year projects and dissertations. York, UK: Higher Education Academy.

Hunter A., S. Larsen, and E. Seymour. 2006. "Becoming a scientist: The role of undergraduate research in students' cognitive personal and professional development." Science Education 91 (1): 36--74.

Jenkins, A., R.Breen, and R.Lindsay . 2003. Reshaping Teaching in Higher Education: Linking Teaching with Research. London: Routledge.

Johnson, L., A. Lee, A., and B. Green. 2000. "The PhD and the Autonomous Self; gender, rationality, and postgraduate pedagogy." Studies in Higher Education 25 (2): 135-47.

Kiley, M., and G. Mullins. 2005. "Supervisors' Conceptions of Research: What Are They?" Scandinavian Journal of Educational Research 49 (3): 245-262. 
Kiley, M., T Moyes, T., and P. Clayton. 2009. "To develop research skills: Honours programmes for the changing research agenda in Australian universities." Innovations in Education and Training International 46 (1): 15-25.

Kyvik, S. and J. Smeby. 1994. "Teaching and Research. The Relationship between the Supervision of Graduate Students and Faculty Research Performance.” Higher Education 28 (2): 227-39.

Lee, A., and B. Green. 2009. “Supervision as metaphor.” Studies in Higher Education 34 (6): 615-630.

Lee, A. 2012. Successful research supervision: Advising students doing research. Oxford, UK: Routledge.

Levy, P. and R. Petrulis, R. 2012. "How do first year university students experience inquiry and research?" Studies in Higher Education 37 (1): 85--101.

Mackinnon, J. 2004. “Academic Supervision: Seeking Metaphors and Models for Quality.” Journal of Further and Higher Education 28 (4): 395-405.

Meyer, J., M. Shanahan, M., and R. Laugksch. 2005. "Students' Conceptions of Research. A qualitative and quantitative analysis." Scandinavian Journal of Educational Research, 49 (3): 225-244.

Miles, M., and A. Huberman. 1994. Qualitative data analysis: An expanded sourcebook. London: Sage.

Nordentoft, H., R. Thomsen, and G. Wichmann-Hansen, G. 2013. "Collective academic supervision: A model for participation and learning in higher education." Higher Education: The International Journal of Higher Education and Educational Planning 65(5): 581-593.

Noy, S. and R. Ray, R. 2012. "Graduate Students' Perceptions of Their Advisors: Is There Systematic Disadvantage in Mentorship?" Journal of Higher Education 83 (6): 876-914.

Ozay, S. 2012. "The dimensions of research in undergraduate learning." Teaching in Higher Education 50 (1): 3--14.

QAA. 2014. UK Quality Code for Higher Education Part A: Setting and Maintaining Academic Standards. The Frameworks for Higher Education Qualifications of UK Degree-Awarding Bodies. https://www.qaa.ac.uk/docs/qaa/quality-code/qualifications-frameworks.pdf (accessed 17 May 2019).

Regan, J. 2012. "The Role Obligations of Students and Lecturers in Higher Education." Journal of Philosophy of Education 46 (1): 14-24.

Renshaw P. 2004. "Dialogic learning, teaching and instruction.” In Dialogic Learning, edited by J. van der Linden, and P. Renshaw, 1-15. Dordrecht: Springer.

Roberts. L., and K. Seaman. 2018. "Good undergraduate dissertation supervision: Perspectives of supervisors and dissertation coordinators." International Journal for Academic Development 23 (1): 28 40.

Robertson, M. 2019. Power and doctoral supervision teams: Developing team building skills in collaborative doctoral research. Abingdon, Oxford: Routledge.

Sambrook, S., J. Stewart, and C. Roberts. 2008. "Doctoral supervision . . . a view from above, below and the middle." Journal of Further and Higher Education 32 (1): 71-84. 
Schweinsberg, S., and P. McManus. 2006. "Exploring the Transition: Coursework to Research-Based Study in the Geography Honours Year." Geographical Research 44: 52 - 62.

Shaw, K., A. Holbrook, and S. Bourke. 2013. "Student experience of final-year undergraduate research projects: an exploration of 'research preparedness'." Studies in Higher Education 38 (5): 711-727.

Skelton, A. 2012. "Value conflicts in higher education teaching." Teaching in Higher Education 17 (3): $257-268$.

Stefani, L., V-N Tariq, D. Heylings, and A. Butcher, A. 1997. "A Comparison of Tutor and Student Conceptions of Undergraduate Research Project Work." Assessment \& Evaluation in Higher Education 22 (3): 271-288.

Stelma, J., and R. Fay. 2014. "Intentionality and developing researcher competence on a UK master's course: An ecological perspective on research education." Studies in Higher Education 39 (4): 517-533.

Styles, I., and A. Radloff. 2001. "The Synergistic Thesis: Student and supervisor perspectives." Journal of Further and Higher Education 25 (1): 97-106.

Tight, M. 2012. Researching higher education. Berkshire, UK: Open University Press.

Todd, M., K. Smith, K., and P. Bannister. 2006. "Supervising a social science undergraduate dissertation: staff experiences and perceptions." Teaching in Higher Education 11 (2): 161-173.

Watson, D. 1983. "Dissertations as a Learning and Teaching Tool: Undergraduate business studies in the UK”. Improving College and University Teaching 31 (4): 182-86.

Vereijken, M., R. Rijst, J. Driel, J., and F. Dekker. 2018. "Novice supervisors' practices and dilemmatic space in supervision of student research projects." Teaching in Higher Education 23 (4): 522-542.

Wisker, G. 2018. "Frameworks and freedoms: Supervising research learning and the undergraduate dissertation." Journal of University Teaching and Learning Practice 15 (4): article 2. https://ro.uow.edu.au/jutlp/ (accessed 27 June 2019).

Wright, A., J. Murray, and P. Geale. 2007. "A phenomenographic study of what it means to supervise doctoral students." Academy of Management Learning and Education 6 (4): 458-474.

Zimbardi, K., and P. Myatt, P. 2014. "Embedding undergraduate research experiences within the curriculum: A cross-disciplinary study of the key characteristics guiding implementation." Studies in Higher Education 39 (2): 233-- 250. 